\title{
Experimental Research Concerning Hydrodynamic Clutches Controlled by Increasing Distance Between Rotors
}

\author{
Wojciech Iwanicki', Ireneusz Musiałek', Karol Osowski2 ${ }^{2}$, \\ Artur Olszak³ ${ }^{3}$ Zbigniew Kęsy², Andrzej Kęsy² \\ 1 University's Branch in Sandomierz, Jan Kochanowski University of Kielce, ul. Żeromskiego 5, 25-369 Kielce, \\ Poland \\ 2 Faculty of Mechanical Engineering, Kazimierz Pulaski University of Technology and Humanities in Radom, ul. \\ Malczewskiego 29, 26-600 Radom, Poland \\ 3 Łukasiewicz Research Network - New Chemical Syntheses Institute, Al. Tysiąclecia Państwa Polskiego 13a, \\ 24-110 Puławy, Poland \\ * Corresponding author's e-mail: k.osowski@vp.pl
}

\begin{abstract}
The article describes the results of experimental research concerning a prototypical hydrodynamic clutch controlled via changes in flow rates of the working fluid. The aim of the research was to collect experimental data to confirm the practical possibility of using such a control method of the hydrodynamic clutch and to compare this with other currently used methods. A change in flow rate of the working fluid was obtained by increasing the distance between rotors. The experimental research was conducted on a test rig built specifically for this purpose. On the basis of the research, the influence of the clutch filling level, the direction of rotation and the temperature of the working fluid on the clutch torque were determined. The experimental research shows that the transferred torque is significantly influenced by the width of the gap between rotors, the rotational speed of the input shaft, the clutch filling degree and the temperature of the working fluid. Thus, these values may be used to control the torque transferred by the hydrodynamic clutch. The temperature of the working fluid is not recommended as a control value due to the fact that it is dependent on the working conditions of the hydrodynamic clutch. On the basis of the test results, it was proven that hydrodynamic clutches controlled by increasing the distance between rotors can be successfully used, for example, in drive systems of wind farms.
\end{abstract}

Keywords: hydrodynamic clutches, drive systems, hydrodynamic clutch control, hydrodynamic clutch tests.

\section{INTRODUCTION}

The hydrodynamic components of transmission systems, such as hydrodynamic torque converters (HTC), hydrodynamic clutches (HC) and hydrodynamic brakes use the kinetic energy of the working fluid to transfer the mechanical energy from the drive motor to the working system of a machine. $\mathrm{HC}$ consist of two rotors: a pump and a turbine placed in a leakproof casing filled with a working fluid. HTC is additionally equipped with stator rotors. In multielement HTCs, it is most common to use one pump rotor and a few turbine rotors, as well as a few stator rotors.
Hydrodynamic components are used in energy industry, machine industry and automotive industry due to their numerous advantages, mainly: damping torsional vibrations, the possibility to work while the output shaft is immobile, and automatic adjustment of output shaft rotation depending on its load.

In technology, the general aim is to achieve the highest possible efficiency of machines and devices. However, there are also drive motors in which the efficiency of a drive system is not relevant due to an excess of energy supplied to the system. This type of system includes the drive systems of electric power generators in wind 
farms. Due to the necessity do maintain a constant frequency of the generated electric power, the rotor of a generator must rotate with a constant rotation speed. When the current frequency is $50 \mathrm{~Hz}$ and there is a single pair of generator poles, the speed is $3000 \mathrm{rpm}$. An unpredictable increase in wind speed results in an increase of rotational speed of the wind farm rotor in relation to a determined rotational speed of the generator, and it results in generating more mechanical energy than necessary. Additionally, the rotational speed of the wind farm rotor must be limited due to the durability of rotor blades.

The article describes the experimental tests performed on a $\mathrm{HC}$ controlled by increasing the distance between pump and turbine rotors. For example, the developed design of the $\mathrm{HC}$ can be used in a wind farm drive. This manner of control, despite its simple construction, has not hitherto been used in hydrodynamic drive systems due to low efficiency. A change in the distance between rotors causes a change in the torque transferred by the $\mathrm{HC}$, subsequently changing a change in speed ratio (i.e. the ratio of the clutch output shaft rotational speed to the clutch input shaft rotational speed). When the rotational speed of a wind farm rotor exceeds the nominal speed, as a result of changes in wind direction or speed, the distance between rotors increases thus causing a decrease in the torque transferred by the clutch. It also causes a change in the kinematic ratio to one that provides the required value of the rotational speed of the output shaft of the clutch connected directly to the generator shaft.

The main aim of works described in the article is increasing the level of knowledge about drive systems by the development of a new control method of the hydrodynamic clutch by increasing the distance between rotors. The concept of the hydrodynamic clutch controlled by increasing the distance between pump and turbine rotors is innovative. This method has not been used in hydrodynamic transmission systems.

\section{LITERATURE REVIEW}

The universality of applications of hydrodynamic components causes the fact that currently multiple research works are conducted, both theoretical and experimental. The aim of these works is to analyse the phenomena occurring within working spaces of rotors and, as a result, to improve the characteristics of the whole hydrodynamic component. In theoretical research, in order to describe the phenomena occurring during the working fluid flow, it is most common to use one dimensional and three dimensional (3D) models constructed with the use of Computational Fluid Dynamics (CFD) numerical methods. Experimental research mainly serves the purpose of drawing up the characteristics which depict the actual performance of hydrodynamic components. The research results are also used to identify and verify the mathematical models of hydrodynamic components.

In order to conduct the calculations of the influence of selected HTC constructional parameters on its characteristics, the study $[1,2]$ uses a one dimensional model with specifically selected coefficients. A similar mathematical model is used by Kęsy and Kęsy [3] in order to improve the production process of HTC rotors. The study $[4,5]$ shows the application of a one dimensional HTC mathematical model in an analysis and an evaluation of damping properties of a vehicle drive system. Jung et al. [6] compared different 3D numerical methods used to describe the flow within the HTC working fluid, such as: the frozen rotor, the sliding mesh method and the mixing plane methods, and subsequently they verify the results of calculations during bench tests. Similar reflections can be found in publications $[7,8]$. The study [9] shows an evaluation of the possibilities to use an a typical working fluid (a mixture of oil and air) within a partially filled $\mathrm{HC}$, on the basis of numerical 3D calculations and experimental research. Schweitzer and Gandham [10] conducted an analysis of a working fluid flow within the HTC using CFD methods, and the results of the numerical calculations are verified on a test station using laser Doppler velocimetry LDV. Similar research is shown in the studies [11, $12,13,14,15,16,17]$. The study [18] shows an optimization of the selection of the entry angle for a pump rotor and the entry angle for a turbine rotor in a HTC. The optimization criterion is the maximal efficiency. The CFD software was used for the optimization. Similar research is described in the article [19], where Liu et al. optimized the HTC blade described using six parameters. The optimization calculations used the CFD method and the design of experiments method (DOE). In turn, the study [20], on the basis of bench tests, a multicriterial optimization of hydrodynamic gear was conducted, assuming an 
objective function which takes into consideration the torque ratio, efficiency and the high efficiency range. The decision variables are as follows: the active diameter, blade angles on an average line, and dimensionless parameters describing the meridional cross-section of the hydrodynamic gear. The multiple-stream model is used as the mathematical model. A genetic algorithm is used for optimization calculations.

A disadvantage of classic hydrodynamic components is a constant dependency of the transferred torque on the rotational speed of rotors. Therefore, in practice, the hydrodynamic components are controlled in different manners, which results from the theoretical dependence describing the torque occurring on the rotors of the hydrodynamic clutch, in the following form [21]:

$$
M_{n}=f\left\{n_{i}^{2}, G\left(r_{i m}, F_{i m}, \beta_{i m}\right), Q(v)\right\} \rho
$$

where: $f$ - function symbol, $n$ - rotational speed of a rotor, $G$ - selected geometrical parameters of the working space, $r$ - radii in meridional section, $F-$ meridional section, $\beta_{n}$ - blade angles on the average line, $Q$ - flow rate of the working fluid within the working space, $\rho$ - working fluid density, $v$ - kinematic viscosity of the working fluid; the index $I$ - represents the number of the rotor blade in the hydrodynamic component; the index $m$ equal to 1 or 2 - represents, respectively, the inlet or outlet of the rotor.

The dependence analysis (1) shows that the control of the torque of a hydrodynamic component is possible via changes in:

- rotational speed of rotors;

- geometric parameters of the working space, including blade angles and radii of the meridional section;

- flow rate of the working fluid within the working space;

- physical parameters of the working fluid.

The simplest manner of controlling the mechanical components is to change the rotational speed on the input shaft, which causes a change of the torque $M$ on the output shaft. The study [22] presents the design of the drive system in which the CVT gear is placed between a drive motor and a HTC in order to change the speed of the pump rotor $n_{1}$.

In practice, a change of geometric parameters of a working space in hydrodynamic components is implemented by rotating the blades - most often the stator blades - around the transverse or the longitudinal axis, in relation to the rotation axis of the rotor $[21,23]$. The working space geometry can also be changed by placing an additional rotor to the hydrodynamic component. This method is applied mainly to change the rotation direction of the output shaft of the hydrodynamic component [24].

The most commonly used manner of changing the flow rate of the working fluid is changing the filling degree of the working fluid in the working space, which causes a change in the torque of the hydrodynamic component [25].

The possibility to control the hydrodynamic components as a result of changes in the physical parameters of the working fluid, creates the possibility to employ the so-called smart fluids (electrorheological or magnetorheological) in which shear stresses change after an electric or a magnetic field occurs, respectively [26]. Prototypical designs of hydrodynamic components controlled in this manner were introduced in the study [27] which described a $\mathrm{HC}$ with electrorheological fluid, and in the study [28] which described a HC with a magnetorheological fluid.

The analysis of the presented control methods shows that the proposed control method of hydrodynamic clutch by increasing the distance between rotors is easy to implement in terms of construction.

An example of usage of a hydrodynamic component in a drive system of a wind farm is depicted in Fig. 1 [29].

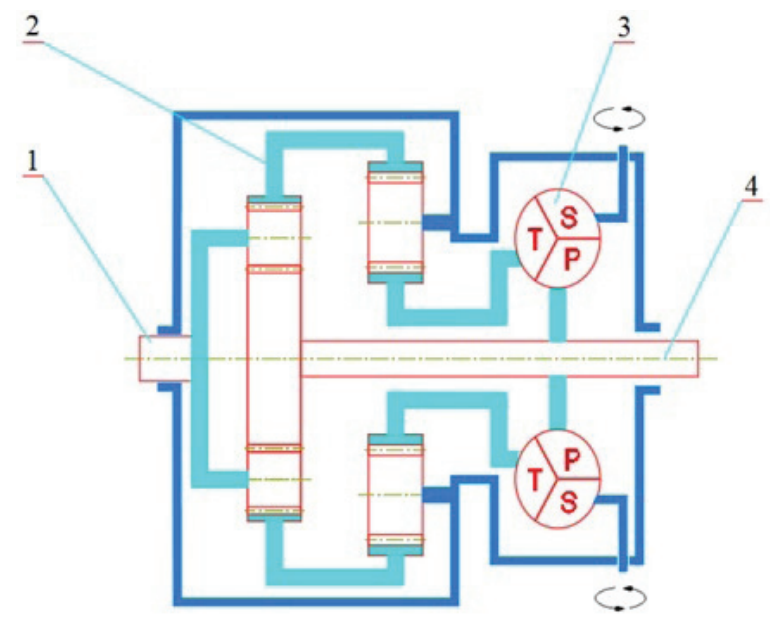

Fig. 1. Drive system of a power generator used in wind farms: 1 - input shaft, 2 - planetary gear, 3 - fixed transmission gear, 4 - hydrodynamic torque converter, 4 - output shaft; $\mathrm{P}$ - pump, $\mathrm{T}$ - turbine, $\mathrm{S}$ - stator 


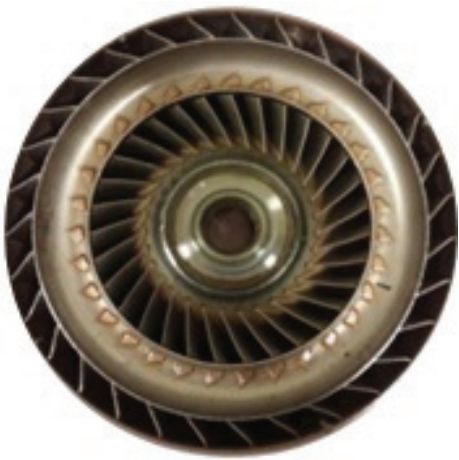

b)

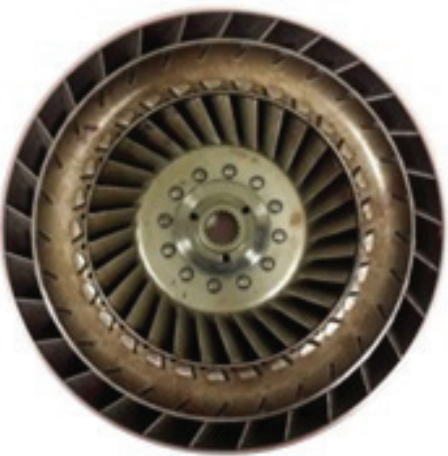

Fig. 2. View on HC rotors with spatially shaped blades: a) pump's rotor, b) turbine's rotor

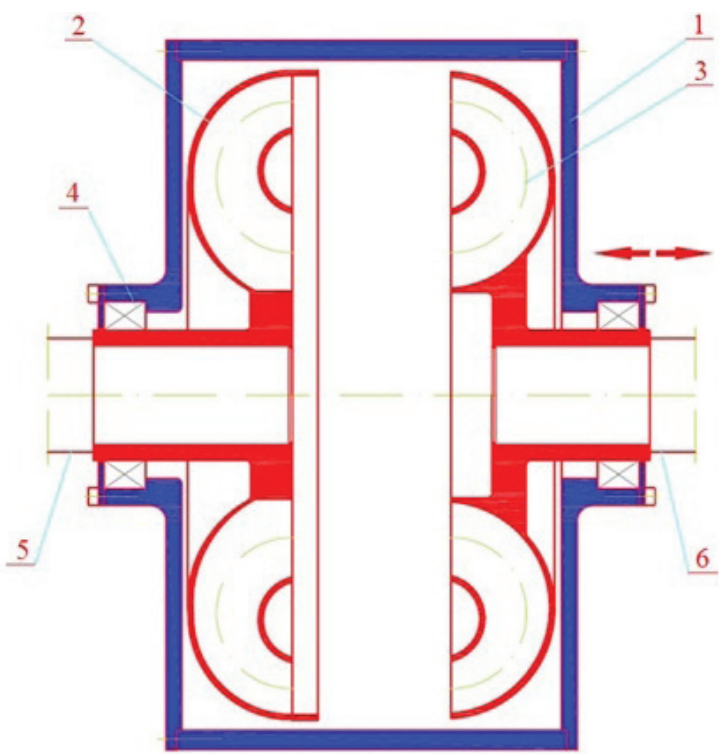

Fig. 3. Prototypical HC: 1 - casing, 2 - pump rotor, 3 - turbine rotor, 4 - bearings, 5 - input shaft, 6 - output shaft
This system, called WinDrive, consists of a HTC controlled via rotating the blades of a stator immobile rotor and two planetary gears. Employing a planetary gear allows dividing the power flux so that only a part of it flows through the HTC.

\section{EXPERIMENTAL RESEARCH}

The experimental research was aimed at collecting the experimental data enabling to evaluate the practical possibilities of controlling the hydrodynamic clutch by increasing the distance between rotors and comparing this control method with other control methods. The tests were conducted on a test station built specifically for this purpose. The test object was a $\mathrm{HC}$ with the rotors the blades of which were spatially shaped and made with pressed sheet metal, Fig. 2.

Table 1. Data concerning the prototypical HC

\begin{tabular}{|l|c|}
\hline \multicolumn{1}{|c|}{ Parameter } & Value \\
\hline Outer diameter of the clutch, $D_{z}$ & $273 \mathrm{~mm}$ \\
\hline Active diameter of the pump rotor and the turbine rotor & $250 \mathrm{~mm}$ \\
\hline Number of blades in the pump rotor and the turbine rotor & 39 \\
\hline Volume of the of the working space, $V$ & $7.6 \mathrm{dcm}^{3}$ \\
\hline Volume of the working fluid & $7 \mathrm{dcm}^{3}$ \\
\hline Rotation direction of rotors & Left/right $^{\circ}$ \\
\hline Entrance angle for the pump rotor, $\beta_{11}$ (left rotations) & $118^{\circ}$ \\
\hline Entrance angle for the pump rotor, $\beta_{11}$ (right rotations) & $62^{\circ}$ \\
\hline Exit angle from the pump rotor, $\beta_{12}$ (left rotations) & $65^{\circ}$ \\
\hline Exit angle from the pump rotor, $\beta_{12}$ (right rotations) & $115^{\circ}$ \\
\hline Entrance angle for the turbine rotor, $\beta_{21}$ (left rotations) & $59^{\circ}$ \\
\hline Entrance angle for the turbine rotor, $\beta_{21}$ (right rotations) & $121^{\circ}$ \\
\hline Exit angle from the turbine rotor, $\beta_{22}$ (left rotations) & $137^{\circ}$ \\
\hline Exit angle from the turbine rotor, $\beta_{22}$ (right rotations) & $43^{\circ}$ \\
\hline
\end{tabular}



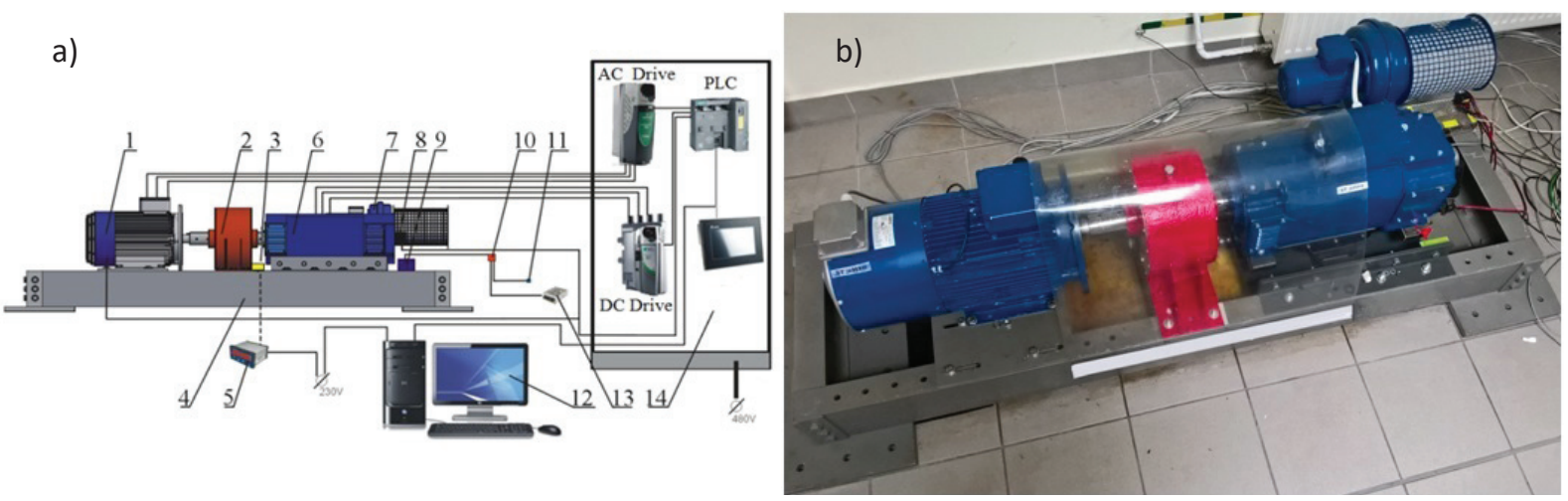

Fig. 4. Test station for HC analysis; a) test station schematic: 1 -AC drive motor, 2 - analysed HC, 3 - temperature sensor, 4 - frame, 5 - digital temperature indicator, 6 -DC brake placed on guideways, 7 - brake cooling system, 8 - encoder, 9 - leadscrew motor, 10 - leadscrew motor's driver, 11 - rotation direction switch for leadscrew, 12 -PC, $13-12 \mathrm{~V}$ power supply, 14 - control cabinet; b) view on mechanical part of test station

Employing rotors with spatially shaped blades in HCs, instead of using ones with radial blades, allows widening the test range of a clutch as a result of obtaining different characteristics of $\mathrm{HC}$ performance for left rotations and right rotations of the input shaft. The HC schematic is shown in Figure 3 . The basic data concerning the prototypical HC is presented in Table 1.

Figure 4 shows the schematic of the test station consisting of a frame, an AC drive motor, a DC motor serving as a brake, a steering system, a rotor sliding system and a computer measurement system registering measurement data in real time.

The pump rotor and the turbine rotor are placed directly on the shafts of the AC drive motor and the break, respectively. In order to increase the distance between rotors, the brake on the shaft of which the turbine rotor is placed, shift horizontally along the station axis on guideways fixed to the station's frame. A leadscrew is used to move the brake. The leadscrew is bearing-mounted on supports permanently fixed to the station frame, and it cooperates with a nut fixed to the brake casing. The leadscrew is propelled with a controlled DC electric motor integrated with a worm gear, Fig. 5.

The change of the filling degree $\psi$ (which is described as a ratio of the working fluid volume within the working space to the whole volume of the working space) is performed with an immobilized drive motor and is realised by adding or removing a specific amount of working fluid through the drain hole of the HC. The measurement was performed with use of a measuring cup.

The control of the drive motor and the brake is realised by control systems AC Drive and DC Drive by Emerson company. The performance of these systems is overseen by a PLC driver which is compatible with the encoders fixed to the shafts

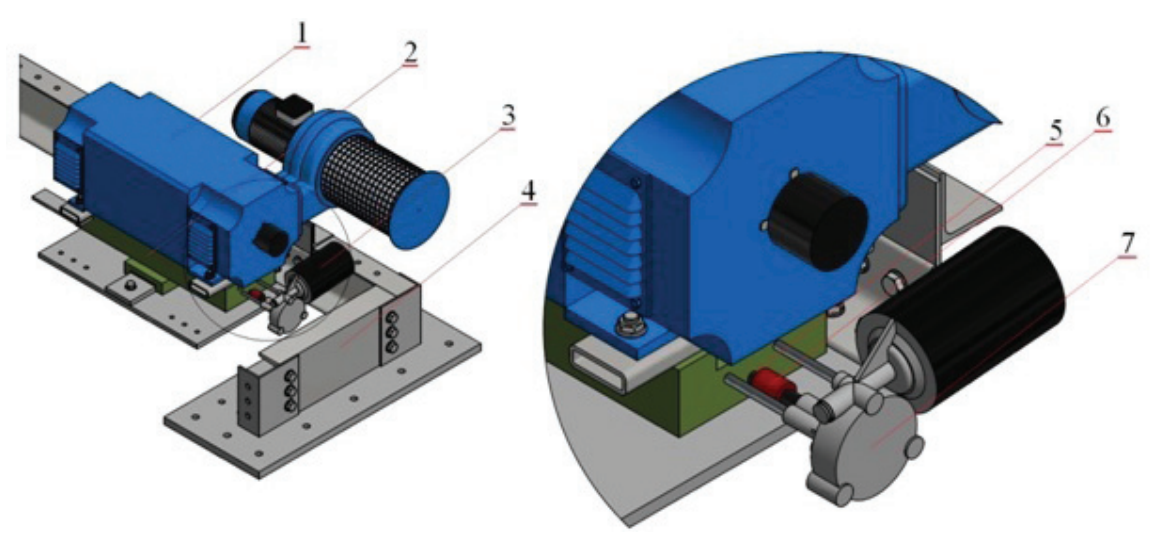

Fig. 5. Realization method of the increase the distance between rotors: 1 - DC motor used as brake, 2 - guide ways, 3 - electric motor with worm gear and lead screw, 4 - station's frame, 5 - lead screw, 6 - coupling, 7 - worm gear 
Table 2. Data concerning the electrical components of the test station used to analyse the HC

\begin{tabular}{|c|c|c|c|}
\hline Usage & Model / type & Type of current & Parameter properties \\
\hline Main drive & Tamel 3SG132S-4-IE2 5.5 kW & AC & $\begin{array}{c}n=1460 \mathrm{rpm} \\
U_{\mathrm{n}}=400 \mathrm{~V}\end{array}$ \\
\hline Brake & Multimoto G11.05 $5.5 \mathrm{~kW}$ & DC & $\begin{array}{c}n=1480 \mathrm{rpm} \\
U_{\mathrm{n}}=400 \mathrm{~V}\end{array}$ \\
\hline Leadscrew drive & BOSCH 058970130 0.1 kW & DC & $\begin{array}{c}n=50 \mathrm{rpm} \\
U=12 \mathrm{~V}\end{array}$ \\
\hline PLC driver & $\begin{array}{c}\text { Siemens Simatic DP } \\
6 E S 7151-8 A B 01-0 A B 0\end{array}$ & AC & $U=230 \mathrm{~V}$ \\
\hline AC Drive control system & Emerson Unidrive SP 1406 & AC & $U_{\mathrm{n}}=400 \mathrm{~V}$ \\
\hline DC Drive control system & Emerson Mentor MP 25A4R & AC & $U_{\mathrm{n}}=400 \mathrm{~V}$ \\
\hline
\end{tabular}

of the electric motors. The basic data concerning the electrical components of the test station is presented in Table 2.

The computer measurement system is integrated with an electric control system of the test station. During the measurements of the torques $M$ and rotational speeds of the shafts of the electric drive motor $n_{1}$ and of the brake $n_{2}$, the data was collected from the PLC driver and then registered with the use of a PC with professional software. During the experimental research with an immobilized HC shaft, in order to measure the torque, a KM $102 \mathrm{~K}$ strain gauge is used, whose measurement range is up to $500 \mathrm{~N}$. The sensor fixed to the station frame is pressed on by a rod fixed to the electric brake axis. The value of the registered force is obtained from an MD 150T digital measuring gauge. The temperature of the working fluid is measured with a Heraeus M222 temperature sensor (produced by Conrad Electronic company) permanently fixed on the outside of the HC.

The experimental research constitutes an important source of information about the performance of the test subject under various working conditions. The theoretical analysis of the issue allows defining the number of knowledge gaps in the existing research methods and indicating new areas to be examined $[30,31]$. It is important to properly plan the research and its implementation according to a specific pattern [32].

On the basis of the results of the $\mathrm{HC}$ experimental research, it is possible to draw up the characteristics which determine how the torque $M$ transferred by the clutch is influenced by the following quantities:

- width of the gap between rotors $(h)$,

- rotational speed of the input shaft $\left(n_{1}\right)$,

- filling degree of the clutch $(\psi)$,

- temperature of the working fluid (T).

The accuracy of the measurements on the working station is shown in Table 3 .

Due to a small mass and a compact design of the $\mathrm{HC}$, and consequently a small thermal capacity and small housing surface, during the research, especially for high values of rotational speed, the temperature of the working fluid

Table 3. Accuracy of measurements performer on the test station

\begin{tabular}{|c|c|}
\hline Measured quantity & Relative measurement error [\%] \\
\hline$h$ & 2 \\
\hline$n_{1}, n_{2}$ & 2 \\
\hline$M$ & 5 \\
\hline$y$ & 5 \\
\hline$T$ & 1 \\
\hline
\end{tabular}

Table 4. Bench test plan for a prototypical HC

\begin{tabular}{|c|c|c|c|c|c|c|}
\hline $\begin{array}{c}\text { No. } \\
\text { of test } \\
\text { series }\end{array}$ & $\mathbf{h ~ [ m m ]}$ & $\begin{array}{c}\mathbf{n}_{1} \\
{[\mathbf{r p m}]}\end{array}$ & $\begin{array}{c}\mathbf{n}_{2} \\
{[\mathbf{r p m}]}\end{array}$ & $\begin{array}{c}\text { Temperature range } \\
\mathbf{T}\left[{ }^{\circ} \mathbf{C}\right]\end{array}$ & $\mathbf{y}[\%]$ & Rotation direction \\
\hline 1. & $h=0$ & $0-1200$ & $n_{2}=0$ & $80-90$ & 92 & Left, right \\
\hline 2. & $h=0$ & $600-1200$ & $n_{2} \neq 0$ & $80-90$ & 92 & Left, right \\
\hline 3. & $h=0$ & $0-1000$ & $n_{2}=0$ & $40-50$ & 92 & Left, right \\
\hline 4. & $h=0$ & 1000 & $n_{2} \neq 0$ & $80-90$ & 84 & Left, right \\
\hline 5. & $0.5 \leq h \leq 50$ & 1000 & $n_{2} \neq 0$ & $80-90$ & 92 & Left, right \\
\hline
\end{tabular}


increased rapidly. Because of that, the measurements were performed in two temperature ranges: $40^{\circ} \mathrm{C}-50^{\circ} \mathrm{C}$ and $80^{\circ} \mathrm{C}-90^{\circ} \mathrm{C}$. In order to increase the credibility of the tests, the measurements were repeated several times, the extreme results were dismissed and the remaining ones were averaged.

The test plan determined after initial analysis is shown in Table 4.

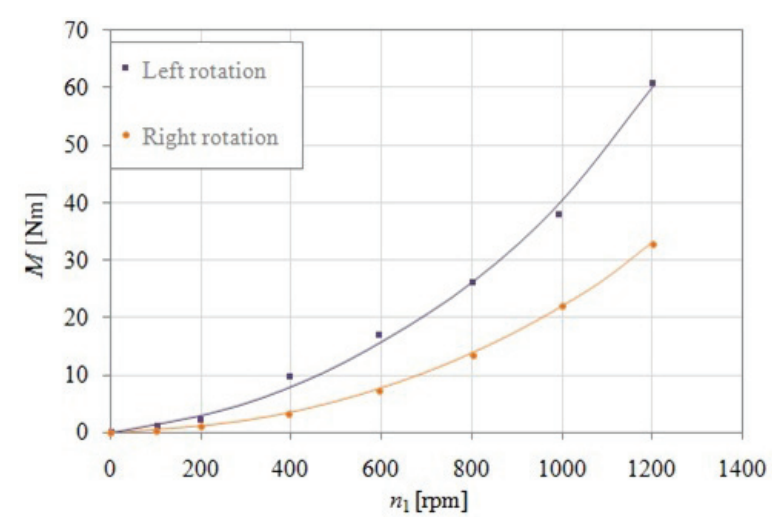

Fig. 6. Dependence $M=f\left(n_{1}\right)$ for different rotation directions of the input shaft; $n_{2}$ $=0, h=0, \psi=92 \%, T=80-90^{\circ} \mathrm{C}$

\section{EXPERIMENTAL RESEARCH RESULTS}

The HC characteristics illustrating the influence of rotation direction of the input shaft $n_{1}$ on the torque transferred by the clutch $M$ for $n_{2}=0$ (test series 1, Table 4) is shown in Fig. 6.

Fig. 7 and Fig. 8. show the characteristics depicting how the torque $M$ is influenced by the speed ratio and input shaft rotations $n_{1}$ for left and right rotations of the input shaft (test series 2, Table 4).

The characteristics depicting the influence of temperature $T$ of the working fluid on the dependence of the torque $M$ on the rotational speed $n_{1}$, for left and right rotations of the input shaft (test series 3, Table 4) is shown in Fig. 9 and Fig. 10, respectively.

Fig. 11 and Fig. 12 show the characteristics depicting the influence of the clutch's filling degree $\psi$ on the transferred torque $M$ (test series 4, Table 5).

The characteristics depicting how the torque $M$ is influenced by the speed ratio $i_{k}$ and by the size of the gap between rotors $h$ for left and right rotations of the input shaft (test series 5, Table 4) are shown in Fig. 13 and Fig. 14, respectively.

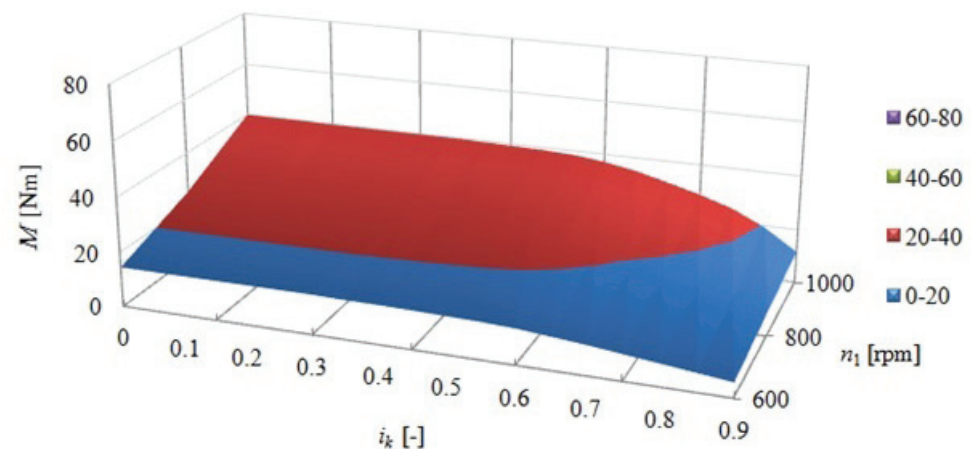

Fig. 7. Dependence $M=f\left(i_{k^{\prime}} n_{1}\right)$ for left rotations of the output shaft; $h=0, \psi=92 \%, T=80-90^{\circ} \mathrm{C}$

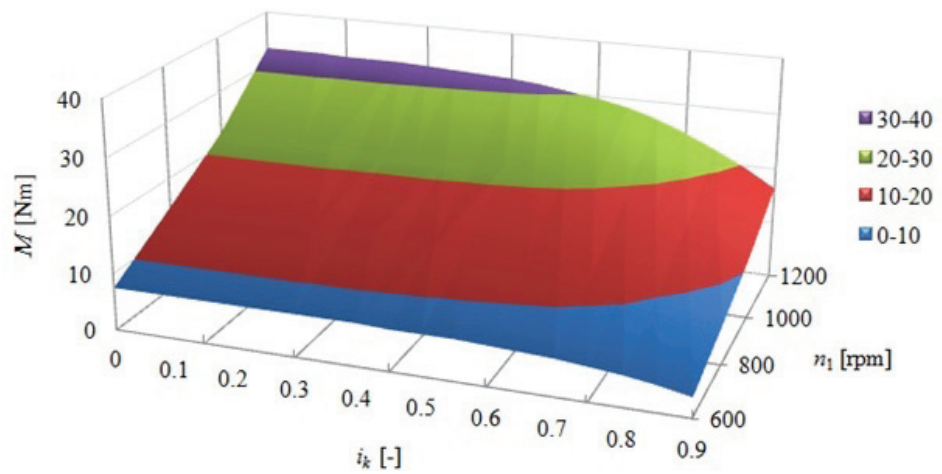

Fig. 8. Dependence $\mathrm{M}=f\left(i_{k}, n_{1}\right)$ for right rotations of the input shaft; $h=0, \psi=92 \%, T=80-90^{\circ} \mathrm{C}$ 


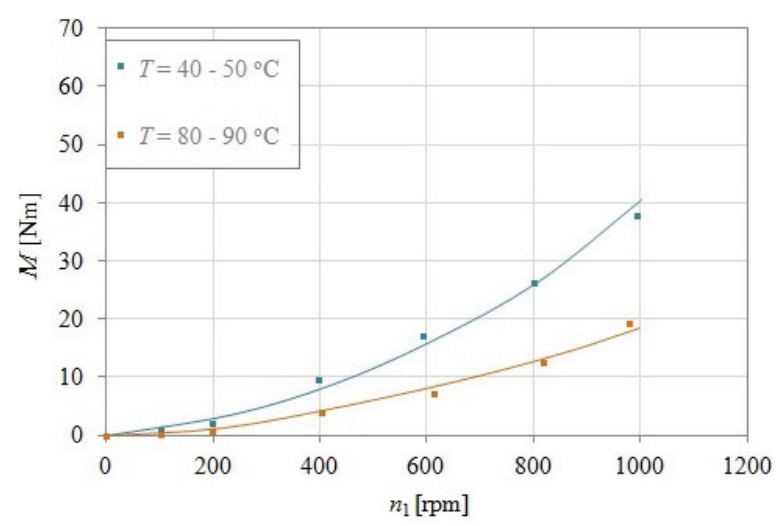

Fig. 9. Dependence of $M=f\left(n_{1}\right)$ for left rotations of the input shaft for different temperatures $T ; h=0, n_{2}=0, \psi=92 \%$

\section{DISCUSSION OF EXPERIMENTAL RESEARCH RESULTS}

The torque $M$ transferred by the $\mathrm{HC}$ for each left rotation direction is significantly larger than for a right rotation direction, Fig. 6 . The difference in the values of the torques $M$ is the greater the higher the rotational speed

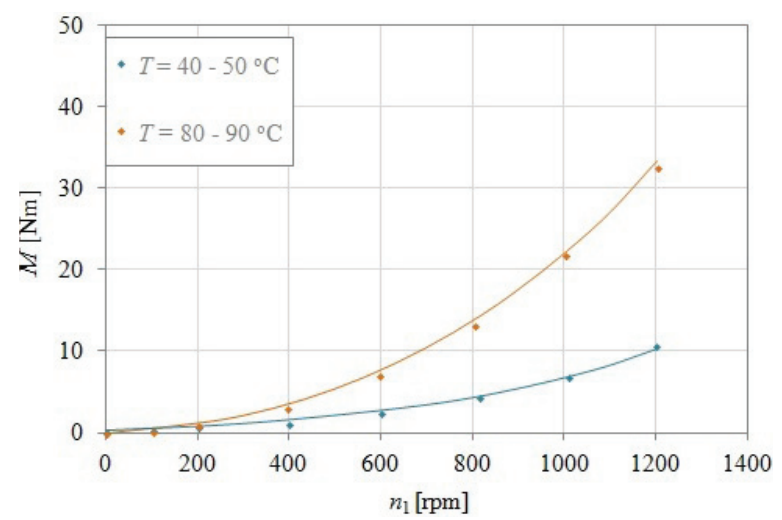

Fig. 10. Dependence of $M=f\left(n_{1}\right)$ for right rotations of the input shaft for different temperatures $T ; h=0, n_{2}=0, \psi=92 \%$

$n_{1}$ of the input shaft is. For the input shaft rotational speed $n_{1}=1000 \mathrm{rpm}$, the torque $M$ is $85 \%$ higher than for right rotations.

The rotational speed of the input shaft has a large influence on the value and waveform of the torque $M$, which is shown in Fig. 7 and Fig. 8. A decrease in the torque $M$ caused by a decrease in the rotational speed of the input shaft $n_{1}$ from

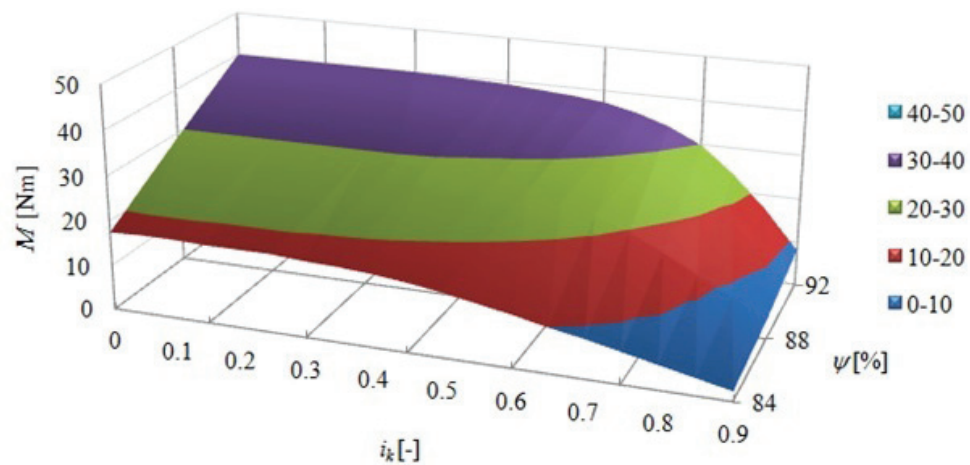

Fig. 11. Dependence of $M=f\left(i_{k^{\prime}} \psi\right)$ for left rotations of the input shaft; $h=0, n_{1}=1000 \mathrm{rpm}, T=80-90^{\circ} \mathrm{C}$

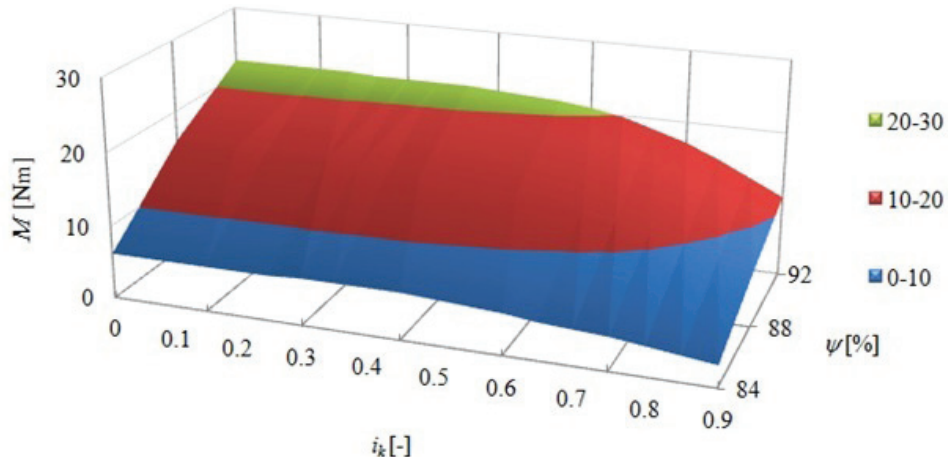

Fig. 12. Dependence of $M=f\left(i_{k} \psi\right)$ for right rotations of the input shaft; $h=0, n_{1}=1000 \mathrm{rpm}, T=80-90^{\circ} \mathrm{C}$ 


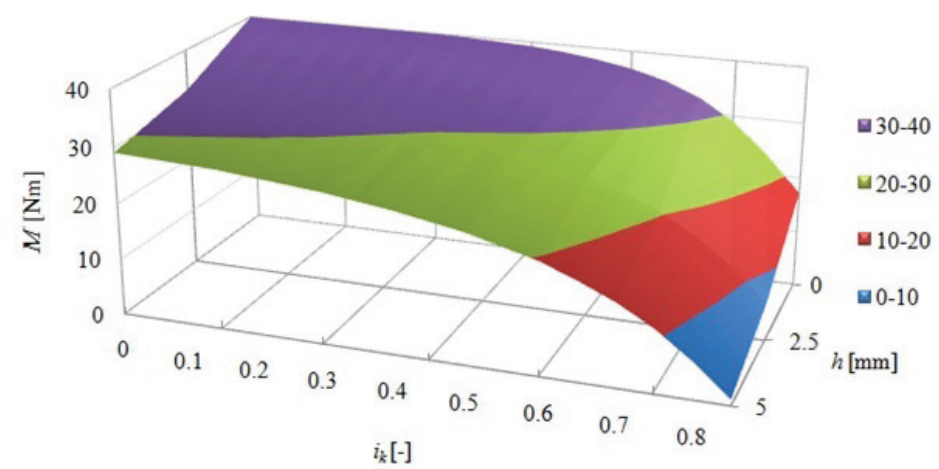

Fig. 13. Dependence of $M=f\left(i_{k^{\prime}} h\right)$ for left rotations of the input shaft; $n_{1}=1000 \mathrm{rpm}, \psi=92 \%, T=80-90^{\circ} \mathrm{C}$

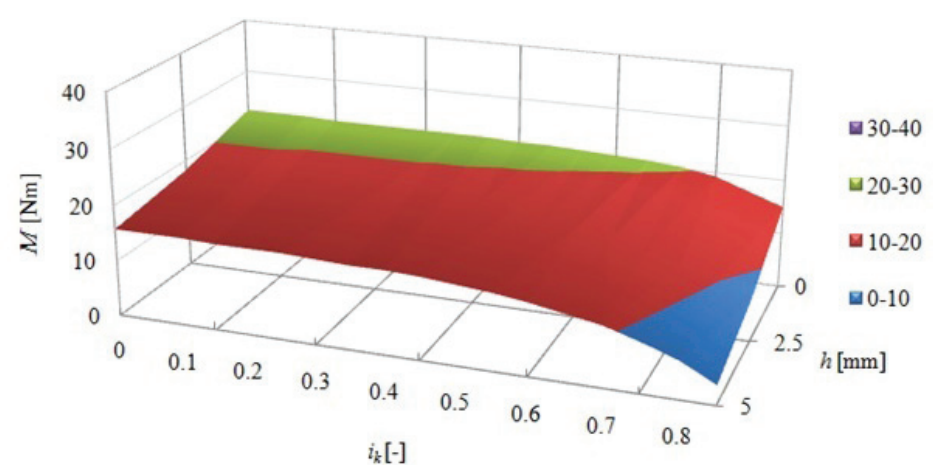

Fig. 14. Dependence of $M=f\left(i_{k^{\prime}} h\right)$ for right rotations of the input shaft; $n_{1}=1000 \mathrm{rpm}, \psi=92 \%, T=80-90^{\circ} \mathrm{C}$

$1000 \mathrm{rpm}$ to $800 \mathrm{rpm}$ is $35 \%$. The waveform of the torque curve $M$ for left rotations of the input shaft is more similar to the quadratic relationship which results from theoretical considerations.

An average $40^{\circ} \mathrm{C}$ decrease in temperature of the working fluid, for speed $n_{1}=1000 \mathrm{rpm}$, contributes to a $50 \%$ decrease of the torque for left rotations of the input shaft and $65 \%$ for right rotations of the input shaft. The increase in the torque $M$ is greater, the higher the rotational speed $n_{1}$ is, see Fig. 9 and Fig. 10.

An $8 \%$ decrease in the value of the filling degree $\psi$ caused a decrease in the value of the transferred torque $M$ for the speed $n_{1}=1000 \mathrm{rpm}$, the maximal decrease is $55 \%$ for left rotations of the input shaft and $70 \%$ for right rotations of the input shaft, see Fig. 11 and Fig. 12.

The characteristics presented in Fig. 13 and Fig. 14 show that for the rotational speed $n_{1}=$ $1000 \mathrm{rpm}$, an increase in the gap width $h$ from 0 to $50 \mathrm{~mm}$ caused a significant decrease in the torque value $M$, wherein the decrease was larger for right rotations of the input shaft $(30 \%)$ than for the left rotations (20\%). Additionally, for left rotations, the influence of the gap width $h$ on the value of the torque decreases when the kinematic ratio increases $i_{k}$. However, for right rotations of the pump rotor, the influence is maintained on a similar level.

The results obtained from the experimental research allow determining a manner in which a $\mathrm{HC}$ with sliding rotors can be used in a drive system of a wind farm with a constant power electric generator. The electric generator needs to have a determined nominal speed $n_{f}$ in order to maintain a constant frequency of the generated electric current. By adjusting the angles of the rotor blades $\beta$ and/or the filling degree $\psi$ it is possible to select a $\mathrm{HC}$ for a drive system, so that with an average wind speed and a determined $\mathrm{HC}$ working temperature, one can obtain the assumed rotational speed of the input shaft of the electric current generator $n_{f}$ when distance $h$ between the pump rotors is around $50 \% h_{\text {max }}$. Then, when the wind speed changes, the nominal speed $n_{f}$ can be maintained as a result of changes in the distance between pump rotors and turbine rotors. However, when the wind speed increases, the torque transferred by the HC should be decreased, i.e. the rotors should be shifted away from each other; 
when the wind speed decreases, the torque transferred by the HC should be increased. i.e. the rotors should be shifted towards each other. The process can be controlled via a control system with feedback, where the controlled value is $n_{f}$, and the controlling value is $h$.

While assessing the operation of the drive system with a hydrodynamic clutch, the range of torque changes and the adjustment time are mainly taken into account. In the tested prototype of a drive system containing a hydrodynamic clutch controlled by rotor shifting, it is possible to achieve the full adjustment range from zero when the rotors are fully extended to the maximum torque when the rotors are fully retracted. The adjustment time depends on the time of the rotor shift, during the tests was a few seconds. The comparison of the test results with the results obtained in the works [33, 34, 25, 29, 27] shows that both the range of torque changes and the adjustment time obtained in the tested prototype of drive system containing a hydrodynamic clutch controlled by rotor shifting do not differ from the value occurring with other methods of regulation, such as: the change rotational speed, the change filling and change flow rate.

\section{CONCLUSIONS}

1. The HC experimental research shows that the transferred torque is significantly influenced by the width of the gap between rotors, the rotational speed of the input shaft, the clutch filling degree and the temperature of the working fluid. Thus, these values may be used to control the torque transferred by the HC. The temperature of the working fluid is not recommended as a regulating value due to the fact that it is dependent on the HC working conditions.

2 . The monotonous decrease of the torque transferred by the $\mathrm{HC}$ as the distance increases between rotors, as observed during the research, suggests that the gaps between rotors should be used as a regulating value for automatic control system with feedback. A wide range of changes in the value of the torque transferred by the $\mathrm{HC}$ (when the gap between the rotors is $50 \mathrm{~mm}$ ) indicates that a technical application of this manner of control will not increase the clutch dimensions significantly.

3. Significant differences in the values of the torque transferred for left and right rotations of the input shaft show that it is advisable to adjust blade angles of the rotors, while building a $\mathrm{HC}$ controlled by sliding pump and turbine rotors.

4. The conducted research shows that the HCs controlled by shifting rotors can be successfully employed in the drive systems of machines, where energy losses caused by controlling are insignificant, for example in the generator drives in wind farms.

5. Further work on the developed control system should be aimed at creating a model of the hydrodynamic clutch and simulating this clutch, for example in a wind farm drive.

\section{REFERENCES}

1. Kęsy Z. and Kęsy A. Application of numerical methods to the modelling of transmission systems with hydrodynamic torque converter. International Journal of Computer Applications in Technology, 31(3/4), 2008, 275 -283. DOI:10.1504/IJCAT.2008.018163

2. Kęsy Z. and Kęsy A. Computer-aided method to calculate coefficients in dynamic equations for multi-element torque converter. International Journal of Vehicle Design, 13(2), 1992, 134 - 143. DOI:10.1504/IJVD.1992.061718

3. Kęsy Z. and Kęsy A. Application of sensitivity methods to the improvement of a hydrodynamic torque converter manufacturing process. International Journal of Computer Applications in Technology, 6(1), 1993, 35 - 38. DOI:10.1504/IJCAT.1993.062612

4. Kęsy A. and Kęsy Z. Damping Characteristics of a transmission system with a hydrodynamic torque converter. Journal of Sound and Vibration, 166(3), 1993, 493 - 506. DOI:10.1006/jsvi.1993.1308

5. Szczepaniak C., Kęsy Z. and Kęsy A. Damping performance of power transmission system with hydraulic torque converter. Vehicle System Dynamics, 20(5), 1991, 283 - 295. DOI:10.1080/00423119108968990

6. Jung J. H., Kang S. and Hur N. A Numerical study of a torque converter with various methods for the accuracy improvement of performance prediction. Progress in Computational Fluid Dynamics An International Journal, 11(3/4), 2011, 261 - 268. DOI:10.1504/PCFD.2011.041027

7. Park In J. and Cho K. R. Numerical flow analysis of torque converter using interrow mixing model. JSME International Journal Series B Fluids and Thermal Engineering, 41(4), 1998, 847 - 854. DOI:10.1299/JSMEB.41.847 
8. Schulz H., Greim R. and Volgmann W. Calculation of three dimensional viscous flow in hydrodynamic torque converter. ASME Journal of Turbomachinery, 118(3), 1996, 578 - 589. DOI:10.1115/1.2836705

9. Luo Y., Zuo Z. G., Liu S. H., Fan H. G. and Zhuge W. L. Numerical simulation of the two-phase flows in a hydraulic coupling by solving VOF model. IOP Conference Series: Materials Science and Engineering, 52, 2013, 1 - 7. DOI:10.1088/1757$899 \mathrm{X} / 52 / 7 / 072022$

10. Schweitzer J. and Gandham J. Computational fluid dynamics in torque converter: validation and application. International Journal of Rotating Machinery, 9, 2003, 411 - 418. DOI:10.1155/ S1023621X03000393

11. Chen J. and $\mathrm{Wu}$ G. Numerical investigation of jet-wake and secondary flows in a hydrodynamic torque converter. SAE Technical Paper, 2017-011335, 2017, 1 - 11. DOI:10.4271/2017-01-1335.

12. Jeyakumar S., Sasikumar M. Computational fluid dynamics simulation of hydraulic torque converter for performance characteristics prediction. International Journal of Scientific Research in Science, Engineering and Technology, 3(6), 2017, 402 408. DOI:10.32628/IJSRSET173697

13. Khafagy A., Saleh I., Elsherief I. Effect of stator shape on the performance of torque converter. 16th International Conference on Aerospace Sciences and Aviation Technology, Cairo, Egypt 2015, 1 14. DOI:10.21608/ASAT.2015.22881

14. Liu C., Li J., Bu W., Ma W., Shen G. and Yuan Z. Large eddy simulation for improvement of performance estimation and turbulent flow analysis in a hydrodynamic torque converter. Engineering Applications of Computational Fluid Mechanics, 12(1), 2018, 635 - 651. DOI:10.1080/19942060.2 018.1489896

15. Liu C., Yang K., Li J., Xu Z., Wang T. Performance improvement and flow field investigation in hydraulic torque converter based on a new design of segmented blades. Proceedings of the Institution of Mechanical Engineers, Part D: Journal of Automobile Engineering, 234(8), 2020, 2162 - 2175. DOI:10.1177/0954407019899507

16. Ota Y., Iio S., Mori Y., Kondo S. Investigation of flattened torque converter performance at low speed ratio. IOP Conference Series: Earth and Environmental Science, 240(9), 2019, $1-6$. DOI:10.1088/1755-1315/240/9/092007

17. Srinivasan C., Joshi D., Dhar S., Wang De M. Dynamic three-dimensional CFD simulation of closed circuit torque converter systems. SAE International Journal of Passenger Cars - Mechanical Systems 9(1), 2016, 289 - 300. DOI:10.4271/2016-01-1345

18. Liu C., Untaroiu A., Wood H. G., Yan Q., Wei W. Parametric analysis and optimization of in- let deflection angle in torque converters. Journal of Fluids Engineering, 137(3), 2015, 1 - 10. DOI:10.1115/1.4028596

19. Liu C., Wei W., Yan Q. and Morgan N. R. Design of experiments to investigate blade geometric effects on the hydrodynamic performance of torque converters. Proceedings of the Institution of Mechanical Engineers, Part D: Journal Automobile Engineering, 233(2), 2017, 276 - 291. DOI: $10.1177 / 0954407017742573$

20. Kęsy A. and Kądziela A. Construction optimization of hydrodynamic torque converter with application of genetic algorithm. Archives of Civil and Mechanical Engineering, 11(4), 2011, 905 - 920. DOI:10.1016/S1644-9665(12)60086-7

21. Stesin S. P. Blade machines and hydrodynamic torque converters. Machinostrjenie, 1990 (in Russian).

22. Hewko L. Automotive traction drive CVTs - An overview. SAE Technical Paper, 861355, 1986, 1 - 16. DOI:10.4271/861355

23. Weston E. B. Theory and design of automotive transmission components. Butterworths, 1967. ISBN-10 : 0408681004

24. Clements H. A. Stopping and reversing high power ships. Proceedings of the ASME 1989 International Gas Turbine and Aeroengine Congress and Exposition. Volume 2: Aircraft Engine; Marine; Microturbines and Small Turbomachinery, Toronto, Ontario, Canada 1989, 1 - 11. DOI:10.1115/89-GT-231

25. Brun K., Meyenberg C., Thorp J. and Kurz R. Hydrodynamic torque converters for oil \& gas compression and pumping applications: basic principles, performance characteristics and applications. 44th Turbomachinery and 31st Pump Symposia, Houston, Texas 2015, 1 - 14. DOI:10.21423/ R14C9Q

26. Kęsy Z. Numerical analysis of torque carried by vehicle hydrodynamic clutch with electrorheological working fluid. International Journal of Vehicle Design, 38(2/3), 2005, 210 - 221. DOI:10.1504/ IJVD.2005.007293

27. Olszak A., Osowski K., Kęsy Z., Kęsy A. Modelling and testing of a hydrodynamic clutch filled with electrorheological fluid in varying degree. Journal of Intelligent Material Systems and Structures, 30(4), 2019, 649-660. DOI:10.1177/1045389X18818780

28. Olszak A., Osowski K., Kęsy Z. and Kęsy A. Investigation of hydrodynamic clutch with MR fluid. Journal of Intelligent Material Systems and Structures, 30(1), 2019, 155 - 168. DOI:10.1177/1045389X18803463

29. Müller H., Pöller M., Basteck A., Tilscher M. and Pfister J. Grid compatibility of variable speed wind turbines with directly coupled synchronous generator and hydro-dynamically controlled gearbox. 
Sixth International Workshop on Large-Scale Integration of Wind Power and Transmission Networks for Offshore Wind Farms, Delft, Netherlands 2006, 307 -315. OSTI ID: 21423397, TRN: NL11E0590, Corpus ID: 107580122

30. Ha K. Innovative blade trailing edge flap design concept using flexible torsion bar and worm drive. HighTech and Innovation Journal, 1(3), 2020, 101106. DOI: 10.28991/HIJ-2020-01-03-01

31. Rahimi F., Aghayari R., Samali B. Application of tuned mass dampers for structural vibration control: A state-of-the-art review. Civil Engineering Journal, 6(8), 2020, 1622 - 1651. DOI:10.28991/ cej-2020-03091571

32. Zhang W., Yang X., Wang T., Peng X., Wang X. Experimental study of a gas engine-driven heat pump system for space heating and cooling. Civil Engineering Journal, 5(10), 2019, 2282 - 2295. DOI:10.28991/cej-2019-03091411

33. Adibi-Asl H., Azad N. L., McPhee J. Math-based torque converter modelling to evaluate damping characteristics and reverse flow mode operation. International Journal of Vehicle Systems Modelling and Testing, 9(1), 2014, 36 - 55. DOI:10.1504/ ijvsmt.2014.059155

34. Adibi-Asl H., Azad N. L., McPhee J. Modeling torque converter characteristics in automatic drivelines: lock-up clutch and engine braking simulation. ASME 2012 International Design Engineering Technical Conferences and Computers and Information in Engineering Conference, Chicago, IL, USA 2012, 1 - 9. DOI:10.1115/DETC2012-70222 